E-ISSN : 2549-6581

DOI: 10.21776/ub.JOIM.2019.003.02.4

Artikel Hasil Penelitian

Diterima : 29 Mei 2019

Direview : 2 Juli 2019

Dimuat : Agustus 2019 - November 2019

\section{OPEN ACCESS}

Journal of Issues in Midwifer

\title{
Perkembangan Bahasa dan Kognitif Anak Usia Prasekolah Antara yang Mengikuti dan Tidak Mengikuti Pendidikan Anak Usia Dini di TK-IT Insan Permata Malang
}

\author{
Aida Novyanti Khoiriah ${ }^{1}$, Fatmawati $^{2}$, Kentri Anggarina Gumanti ${ }^{3}$ \\ 1)Program Studi S1 Kebidanan, FakultasKedokteran, Universitas Brawijaya, Email: \\ aidakhoiriah@gmail.com, Tlp: +628998038898 \\ ${ }^{2}$ Program Studi S1 Kebidanan, Fakultas Kedokteran, Universitas Brawijaya, Email: \\ fatmawatibetty26@gmail.com \\ 3 Program Studi S1 Kebidanan, Fakultas Kedokteran, Universitas Brawijaya, Email: \\ kentri.ag@gmail.com
}

\begin{abstract}
Preschool children, aged 4-6 years old being in the golden age period when they experiencing rapid growth and development. Development experienced include language and cognitive development. Language development in each individual child depends on neurological abilities. Children who have good cognitive development will have a big chance to speak in good language. Early Childhood Education supports optimal growth and development of children, because Early Childhood Education's environment has a lot of stimulation. This study aims to determine the differences in language and cognitive development of preschool children between who did attend and did not attend Early Childhood Education in TK - IT Insan Permata Malang. This study used analytical observations method with cross sectional approach and used total sampling technique with 47 children as respondents which were studied in November 2018. The study used two instruments, which wereDenver Development Screening Test II to measured language development and cognitive questionnaire to measured cognitive development. Non Parametric Chi Square statisctical test were used in this Study. The result showed normal category language development in children who did attend Early Childhood Education (95.7\%) significantly higher than children who did not $(41,7 \%) P$ value 0,000 . Good development cognitive in children who attended Early Childhood Education (95,7\%) significantly higher than children who did not $(37,5 \%) P$ value 0,000 . So there were significant differences between the language and cognitive development of children who did attend Early Childhood Education with did not. The results of normal children's language development were $68,1 \%$, and good children's cognitive development was $66 \%$.
\end{abstract}

Keywords : Cognitive development, Early Childhood Education, Language development,

\section{ABSTRAK}

Anak prasekolah yaitu usia 4-6 tahun sedang dalam periode the golden age yaitu anak mengalami pertumbuhan dan perkembangan yang pesat. Perkembangan yang dialami antara lain perkembangan bahasa dan kognitif. Perkembangan bahasa pada tiap 
individu anak bergantung pada kemampuan neurologik, anak yang memiliki perkembangan kognitif baik berpeluang besar dapat berbicara dan berbahasa dengan baik. PAUD menunjang pertumbuhan dan perkembangan anak secara optimal, karena lingkungan PAUD kaya akan stimulasi. Penelitian ini bertujuan untuk mengetahui perbedaan perkembangan bahasa dan kognitif anak usia prasekolah antara yang mengikuti dengan yang tidak mengikuti PAUD di TK-IT Insan Permata Malang. Penelitian ini menggunakan metode observasi analitik dengan pendekatan cross sectional. Sampel dipilih menggunakan teknik total sampling. Jumlah responden 47 anak terdiri dari 23 anak yang mengikuti PAUD dan 24 anak yang tidak mengikuti PAUD yang diteliti pada bulan November 2018. Instrumen penelitian yaitu Denver Development Screening Test I/ untuk mengukur perkembangan bahasa dan lembar kuesioner perkembangan kognitif untuk mengukur perkembangan kognitif. Penelitian ini menggunakan uji statistik non parametric yaitu Chi Square. Hasil penelitian menunjukkan perkembangan bahasa kategori normal pada anak yang mengikuti PAUD (95,7\%) lebih tinggi dibanding anak yang tidak mengikuti PAUD (41,7\%) dengan hasil signifikasi $P$ value $=0,000$. Perkembangan kognitif baik pada anak yang mengikuti PAUD (95,7\%) lebih tinggi dibanding anak yang tidak mengikuti PAUD $(37,5 \%)$ dengan hasil signifikasi $P$ value $=0,000$.

Kata kunci: Perkembangan Kognitif, PAUD, Perkembangan Bahasa

*Korespondensi:Aida Novyanti Khoiriah. Surel: aidakhoiriah@gmail.com

\section{PENDAHULUAN}

Masa anak-anak dengan rentang usia 4-6 tahun disebut sebagai anak usia prasekolah dan merupakan fondasi awal untuk anak dapat mengalami pertumbuhan dan perkembangan. Pada usia ini anak sedang mengalami masa keemasan (the golden age) yaitu masa terpenting untuk anak melakukan proses pertumbuhan dan perkembangan yang sangat pesat karena fungsi fisik dan psikis yang sudah matur sehingga anak dapat merespon dengan baik berbagai macam aktivitas yang terjadi pada lingkungannya ${ }^{4}$.

$$
\text { Perkembangan bahasa }
$$

berkaitan dengan perkembangan kognitif karena perkembangan bahasa pada setiap individu anak bergantung pada kemampuan neurologik dan perkembangan kognitif yang dapat mempengaruhi tahapan perkembangan bahasa. Anak yang memiliki fungsi kognitif baik maka berpeluang lebih besar untuk dapat berbahasa dan berbicara dengan baik ${ }^{5}$.

$$
\text { Untuk menunjang }
$$

pertumbuhan dan perkembangan maka anak harus mendapat stimulasi-stimulasi yang dapat diperoleh dengan cara mengikuti program prasekolah. Pendidikan yang diberikan dengan terencana dapat membantu anak dalam mengembangkan potensi dan dapat menstimulasi perkembangan anak antara lain perkembangan motorik halus, motorik kasar, sosial, emosi, bahasa, dan kognitif sebagai hasil dalam pembentukan kecerdasan anak6.

Menurut Depkes (2015) berdasarkan info tumbuh kembang 2016 Sekitar 8\% dari 9,4 juta anak Indonesia mengalami keterlambatan bicara dan bahasa. Pada anak usia 5 tahun, terdapat $17 \%$ anak dengan gangguan bicara dan bahasa, $6,4 \%$ mengalami keterlambatan bicara, $6 \%$ mengalami keterlambatan bahasa, dan $4,6 \%$ yang mengalami keterlambat bicara dan bahasa). 
Selain itu gangguan perkembangan bahasa yaitu gagap terjadi sebanyak $4-5 \%$ pada anak usia 3-5 tahun. Berdasarkan hasil penelitian yang dilakukan oleh Dr. Benjamin S. Bloom, Professor of Education, University of Chicago menjelaskan bahwa anak usia 4 tahun mengalami peningkatan kecerdasan yang signifikan yaitu $50 \%$, usia 8 tahun mencapai $80 \%$ dan tingkat intelegensi akan komplit terbentuk pada usia 18 tahun.

Pendidikan anak usia dini (PAUD) merupakan salah satu program pendidikan dari pemerintah yang ditunjukkan untuk anak prasekolah sebagai fasilitas yang dapat menunjang pertumbuhan dan perkembangan anak secara optimal. Menurut data statistik PAUD tahun 2016/2017 lembaga PAUD di Indonesia terdiri dari 105.005 lembaga, dan di Jawa Timur terdiri dari 19.264 lembaga. Proses pembelajaran PAUD mengimplementasikan kurikulum 2013 dengan pedekatan saintifik dan penilaian otentik. Stimulus yang diberikan di PAUD lebih intensif dibandingkan dengan lingkungan luar PAUD?.

Pada catatan United Nations Educational Scientific and Cultural Organizations (UNESCO) (2013), angka partisipasi PAUD di Indonesia menduduki peringkat terendah dengan jumlah partisipasi 22\% dibandingkan dengan 5 negara berpenghasilan rendah di Asia lainnya seperti Filipina sebesar $27 \%$, Vietnam sebesar $43 \%$, Thailand sebesar $86 \%$ dan Malaysia dengan partisipasi terbesar yaitu $89 \%$.

Berbagai hambatan pada program PAUD yaitu kurangnya pengetahuan orang tua, keterbatasan kondisi ekonomi, jarak rumah ke sekolah yang relatif jauh sehingga menghabiskan biaya lebih banyak untuk sekolah dan transportasi, orang tua yang memiliki tingkat kesibukan tinggi sehingga tidak memiliki waktu untuk menunggu anaknya dan lebih memilih untuk bekerja ${ }^{8}$.

Berdasarkan hasil penelitian yang dilakukan oleh Mustika (2011), ada perbedaan perkembangan bahasa antara anak yang mengikuti dengan yang tidak mengikuti PAUD. Anak yang mengikuti PAUD akan mendapatkan stimulusi yang lebih terarah dan akan berpengaruh terhadap perkembangan anak ${ }^{9}$.Penelitian yang dilakukan oleh Anggraeni (2015), terdapat 41 responden menunjukkan bahwa anak yang mengikuti PAUD memiliki perkembangan kognitif baik $(28,4 \%)$ lebih banyak dibandingkan dengan anak yang tidak mengikuti PAUD $(5,7 \%)^{10}$.

Berdasarkan hasil studi pendahuluan yang dilakukan oleh peniliti pada bulan Juli 2018 di TK-IT Insan Permata Malang terhadap 15 anak usia 4-5 tahun, didapatkan 4 anak mengalami keterlambatan perkembangan bahasa dan 4 anak dengan perkembangan kognitif cukup. Berdasarkan permasalahan perkembangan bahasa dan kognitif pada anak, peneliti tertarik melakukan penelitian "Perbedaan Perkembangan Bahasa dan Kognitif Anak Usia Prasekolah antara yang Mengikuti dengan yang Tidak Mengikuti Pendidikan Usia Dini di TK-IT Insan Permata Malang".

\section{METODE PENELITIAN Rancangan/Desain Penelitian}

Penelitian ini menggunakan desain penelitian analitik 
obsevasional dengan metode pendekatan cross sectional. Variabel yang digunakan meliputi variabel independen yaitu anak usia prasekolah yang mengikuti PAUD dan yang tidak mengikuti PAUD. Variabel Dependen yaitu perkembangan bahasa dan kognitif anak usia prasekolah.

\section{Sumber Data}

Sumber data penelitian diperoleh melalui pengisian kuesioner biodata anak dan orang tua, DDST II (Denver Development Screening Test II), dan lembar penilaian kognitif yang diadaptasi DEPDIKNAS 2003.

\section{Sasaran Penelitian}

Populasi dalam penelitian ini adalah anak usia prasekolah kelompok A (4-5 tahun) di TK-IT Insan Permata Malang berjumlah 47 reponden terdiri dari 23 anak yang mengikuti PAUD dan 24 anak yang tidak mengikuti PAUD yang memenuhi kriteria inklusi dan eksklusi. Teknik sampling yang digunakan adalah Total sampling.

\section{Pengembangan Instrumen dan Teknik Pengumpulan Data}

Instrumen penelitian yang digunakan dalam penelitian meliputi pengisian kuesioner biodata anak dan orang tua, DDST II (Denver Development Screening Test II), dan lembar penilaian kognitif yang diadaptasi DEPDIKNAS 2003.

\section{Teknik Analisis Data}

Analisis data pada penelitian ini menggunakan uji statistik Chi Square untuk menguji hipotesis. Nilai $\alpha \leq 0,05$ dengan tingkat kepercayaan 95\%. Data diolah menggunakan SPSS for windows.

\begin{abstract}
Penelitian ini sudah melalui proses ethical clearance dan dinyatakan laik etik oleh komisietikpenelitiankesehatanFakult asKedokteranUniversitasBrawijaya Malang No. 240/EC/KEPK-S1KB/10/2018.
\end{abstract}

\section{HASIL PENELITIAN \\ Analisis Univariat \\ 1. Karakteristik Responden}

Tabel 1. Distribusi Karakteristik Responden

\begin{tabular}{lcc}
\hline $\begin{array}{l}\text { Karakteristik } \\
\text { Responden }\end{array}$ & $\mathbf{N}$ & $\%$ \\
\hline $\begin{array}{l}\text { Jenis Kelamin } \\
\text { Laki-Laki }\end{array}$ & 24 & 51,1 \\
$\quad$ Wanita & 23 & 48,9 \\
$\begin{array}{l}\text { Usia (tahun) } \\
4 \text { tahun }\end{array}$ & 22 & 46,8 \\
5 tahun & 25 & 53,2 \\
\hline
\end{tabular}

Pada tabel 1 menjelaskan
tentang tentang responden. Hasil yang diperoleh bahwa respondenberjenis kelamin laki-laki lebih banyak yaitu 24 anak $(51,1 \%)$ dan usia terbanyak adalah usia 5 tahun sebanyak 25 anak $(53,2 \%)$.

\section{Karakteristik Orang Tua}

Tabel 2. Distribusi Karakteristik Orang Tua

\begin{tabular}{lcc}
\hline $\begin{array}{l}\text { Karakteristik Orang } \\
\text { Tua }\end{array}$ & $\mathbf{N}$ & $\%$ \\
\hline $\begin{array}{l}\text { Pendidikan } \\
\text { SMA }\end{array}$ & 13 & 27,7 \\
D1 & 2 & 4,3 \\
D2 & 5 & 10,6 \\
D3 & 13 & 19,1 \\
S1 & 14 & 29,8 \\
S2 & 4 & 8,5 \\
\hline
\end{tabular}




\begin{tabular}{lcc}
\hline Pekerjaan & 26 & 55,3 \\
IRT & 4 & 8,5 \\
Guru & 4 & 8,5 \\
Dosen & 3 & 6,4 \\
PNS & 7 & 14,9 \\
Wiraswasta & 3 & 6,4 \\
\hline
\end{tabular}

Pada tabel 2 menjelaskan tentang karakteristik orang tua. Hasil yang diperoleh adalah pendidikan terakhir orang tua terbanyak yaitu S1 sebanyak 14 ibu $(29,8 \%)$ dan mayoritas ibu tidak bekerja yaitu ibu rumah tangga sebanyak 26 ibu $(55,3 \%)$.

\section{Keikutsertaan PAUD}

Tabel 2. Keikutsertaan PAUD

$\begin{array}{ccc}\text { Keikutsertaan PAUD } & \mathbf{N} & \% \\ \text { PAUD } & 23 & 48,9 \\ \text { Tidak PAUD } & 24 & 51,1\end{array}$

Berdasarkan tabel 3
menjelaskan jumlah anak yang
mengikuti PAUD dan yang tidak
mengikuti PAUD. Hasil yang
diperoleh anak yang mengikuti
PAUD sebanyak 23 anak (48,9\%)
dan yang tidak mengikuti PAUD
sebanyak 24 anak $(51,1 \%)$.

\section{Perkembangan Bahasa dan Kognitif Anak Usia Prasekolah Antara Yang Mengikuti dengan Yang Tidak Mengikuti PAUD}

\begin{tabular}{lcccccccc}
\hline Keikutsertaan & \multicolumn{4}{c}{ Perkembangan Bahasa } & \multicolumn{3}{c}{ Total } \\
\cline { 2 - 10 } & Normal & $\mathbf{f ( \% )}$ & Suspect & $\mathbf{f}(\%)$ & Untestable & $\begin{array}{c}\mathbf{f} \\
(\%)\end{array}$ & $\mathbf{n}$ & $\mathbf{f ( \% )}$ \\
\hline PAUD & 22 & 95,7 & 1 & 4,3 & 0 & 0,0 & 23 & 100 \\
\hline Tidak PAUD & 10 & 41,7 & 14 & 58,3 & 0 & 0,0 & 24 & 100 \\
\hline Total & 32 & 68,1 & 15 & 31,9 & 0 & 0,0 & 47 & 100 \\
\hline
\end{tabular}

\begin{tabular}{lcccccccc} 
& \multicolumn{9}{c}{ Perkembangan Kognitif } & \multicolumn{2}{c}{ Total } \\
\cline { 2 - 9 } Keikutsertaan & Baik & $\mathbf{f ( \% )}$ & Cukup & $\mathbf{f}(\%)$ & Kurang & $\mathbf{f ( \% )}$ & $\mathbf{n}$ & $\mathbf{f ( \% )}$ \\
& & & & & & & & \\
\hline PAUD & 22 & 95,7 & 1 & 4,3 & 0 & 23 & 100 \\
\hline Tidak PAUD & 9 & 37,5 & 14 & 58,3 & 1 & 4,2 & 24 & 100 \\
\hline Total & 31 & 66,0 & 15 & 31,9 & 1 & 2,1 & 47 & 100 \\
\hline
\end{tabular}

Berdasarkan tabel 4
diketahui perkembangan bahasa pada anak yang mengikuti PAUD pada kategori normal yaitu sebanyak 22 anak (95,7\%), dan kategori suspect 1 anak (4,3\%). Anak yang tidak mengikuti PAUD pada kategori normal berjumlah 10 anak $(41,7 \%)$, kategori suspect 14 anak (58,3\%), sedangkan kategori untestable pada anak yang mengikuti PAUD maupun tidak mengikuti PAUD tidak ada $(0,0 \%)$. Pada data tersebut menunjukkan bahwa anak yang mengikuti PAUD lebih banyak pada perkembangan bahasa kategori normal sebanyak 22 anak sedangkan anak yang tidak mengikuti PAUD lebih banyak pada kategori suspect yaitu sebanyak $14 \quad$ anak. 


\section{Analisis Bivariat}

\section{Perbedaan Perkembangan Bahasa dan Kognitif Anak Usia Prasekolah antara yang Mengikuti dengan yang Tidak Mengikuti PAUD}

\begin{tabular}{|c|c|c|c|c|c|c|c|c|c|}
\hline \multirow{2}{*}{$\begin{array}{c}\text { Keikut } \\
\text { sertaan }\end{array}$} & \multicolumn{6}{|c|}{ Perkembangan Bahasa } & \multicolumn{2}{|c|}{ Total } & \multirow{2}{*}{$\begin{array}{l}\mathbf{P} \\
\text { Value } \\
0,000\end{array}$} \\
\hline & Normal & $f(\%)$ & Suspect & $f(\%)$ & $\begin{array}{c}\text { Untes } \\
\text { table }\end{array}$ & $f(\%)$ & $\mathbf{n}$ & $f(\%)$ & \\
\hline PAUD & 22 & 95,7 & 1 & 4,3 & 0 & 0,0 & $\begin{array}{l}2 \\
3\end{array}$ & 100 & \\
\hline $\begin{array}{l}\text { Tidak } \\
\text { PAUD }\end{array}$ & 10 & 41,7 & 14 & 58,3 & 0 & 0,0 & $\begin{array}{l}2 \\
4\end{array}$ & 100 & \\
\hline Total & 32 & 68,1 & 15 & 31,9 & 0 & 0,0 & $\begin{array}{l}4 \\
7\end{array}$ & 100 & \\
\hline \multirow{2}{*}{$\begin{array}{c}\text { Keikut } \\
\text { sertaan }\end{array}$} & \multicolumn{6}{|c|}{ Perkembangan Kognitif } & \multicolumn{2}{|c|}{ Total } & P \\
\hline & Baik & $f(\%)$ & Cukup & $f(\%)$ & Kurang & f (\%) & $\mathbf{n}$ & $f(\%)$ & 0,000 \\
\hline PAUD & 22 & 95,7 & 1 & 4,3 & 0 & 0,0 & 23 & 100 & \\
\hline $\begin{array}{l}\text { Tidak } \\
\text { PAUD }\end{array}$ & 9 & 37,5 & 14 & 58,3 & 1 & 4,2 & 24 & 100 & \\
\hline Total & 31 & 66,0 & 15 & 31,9 & 0 & 4,2 & 47 & 100 & \\
\hline
\end{tabular}

Berdasarkan tabel uji statistik Chi Square menunjukkan hasil perkembangan bahasa dan kognitif anak dengan nilai signifikasi 0,000 . Hasil menunjukkan nilai signifikasi ataup value $0,000<0,05$ maka menunjukkan terdapat perbedaan bermakna antara perkembangan bahasa anak yang mengikuti PAUD dengan yang tidak mengikuti PAUD.

\section{PEMBAHASAN}

Berdasarkan hasil penelitian menunjukkan hasil nilai signifikasi atau $p$ value $0.000<0,05$. Hal tersebut menunjukkan bahwa terdapat perbedaan bermakna perkembangan bahasa dan kognitif anak usia prasekolah antara yang mengikuti PAUD dengan yang tidak mengikuti PAUD.

Berdasarkan hasil penelitian dari 47 anak yang terdiri dari 23 anak mengikuti PAUD dan 24 anak tidak mengikuti PAUD. Pada perkembangan bahasa anak yang mengikuti PAUD kategori normal sebanyak 22 anak (95,7\%) sedangkan anak yang tidak mengikuti PAUD perkembangan bahasa kategori normal sebanyak 10 anak (41,7\%). Pada perkembangan kognitif anak yang mengikuti PAUD kategori baik sebanyak 22 anak (95,7\%) sedangkan anak yang tidak mengikuti PAUD perkembangan kognitif kategori baik sebanyak 9 anak $(37,5 \%)$.

Faktor yang mempengaruhi perkembangan anak terdiri dari faktor internal dan eksternal. Pada penelitian ini faktor internal yang mempengaruhi perkembangan bahasa dan kognitif anak yaitu usia anak. Semakin bertambah usia anak maka akan semakin bertambah juga kosakata yang dimiliki anak. Kosakata yang dimiliki anak mempengaruhi anak dalam 
berbicara dan berbahasa, semakin banyak kosakata yang dimiliki maka akan semakin baik dalam berbicara. Pada usia prasekolah anak memiliki peningkatan sebanyak $50 \%$ yang berpengaruh pada perkembangan kognitif dan akan semakin bertambah hingga mencapai maksimal pada usia 18 tahun.

Faktor eksternal yang mempengaruhi perkembangan bahasa dan kognitif anak pada penelitian ini yaitu pendidikan terakhir orang tua. lbu dengan pendidikan terakhir tinggi akan mengharapkan anaknya bisa menjadi generasi yang lebih baik dari orang tuanya. Pendampingan, pembelajaran yang tepat, pendidikan yang baik menjadi salah satu penunjang untuk anak mencapai keberhasilan dalam perkembangan bahasa dan kognitif. lbu yang memiliki pendidikan tinggi akan memiliki informasi dan wawasan yang lebih luas sehingga dapat melakukan stimulasi yang tepat untuk perkembangan

Orang tua yang
mengikutsertakan anak ke PAUD anak akan mendapatkan stimulasi yang terarah, anak yang banyak mendapatkan stimulasi akan memiliki perkembangan yang lebih baik dibandingkan dengan anak yang kurang mendapatkan stimulasi bahkan tidak mendapatkan stimulasi. Berbagai stimulasi bisa didapatkan melalui panca indera yaitu dengan melihat, mendengar, merasakan, mencium, dan juga meraba. Stimulasi tersebut bisa diperoleh anak dengan mengikuti PAUD dan berdasarkan Permendikbud Nomor 146 Tahun 2014 dengan standar Pendidikan Anak Usia Dini bahwa lembaga PAUD harus memenuhi beberapa syarat yaitu pembelajaran berpusat pada anak, pembelajaran melalui bermain yang terencana dan berkesinambungan, dan tenaga pendidik juga harus memenuhi beberapa standar seperti memiliki kualifikasi akademik dan kompetensi, ijazah D4 atau S1 dalam bidang PAUD, dan memiliki sertifikat Pendidikan Profesi Guru (PPG) dari perguruan tinggi yang terakreditasi sehingga dengan standar tersebut akan berdampak baik untuk perkembangan kognitif anak.

\section{SIMPULAN}

Terdapat hubungan yang bernakna perkembangan bahasa dan kognitif anak usia prasekolah antara yang mengikuti dengan yang tidak mengikuti PAUD di TK-IT Insan Permata Malang. Anak yang mengikuti PAUD memiliki perkembangan bahasa dan kognitif yang lebih baik dibandingkan dengan anak yang tidak mengikuti PAUD.

\section{SARAN}

Instrumen pada penelitian berikutnya dapat menggunakan SDIDTK untuk mengetahui faktorfaktor lain dari perkembangan anak.

\section{DAFTAR PUSTAKA}

1. Suyadi. Teori Pembelajaran Anak Usia Dini Dalam Kajian Neurosains.

Rosda; 2014.

2. Mulyasa HE. Manajemen PAUD. Bandung: PT. Remaja Rosdakarya; 2012.

3. Wong DL. Buku Ajar Keperawatan Pediatrik. Volume 1, edisi 6. Penerbit Buku Kedokteran EGC : Jakarta; 2009. 
4. Dewi RC, Oktiawati A, dan Saputri LD.Teori \& Konsep Tumbuh Kembang Bayi. Toddler, Anak dan Usia Remaja.

5. Depkes. Profil Kesehatan Indonesia Tahun 2015.

6. Bloom BS. Taxonomy of Educational Objectives: The Classification of Educational Goals, Handbook I Cognitive Domain. New York : Longmans, Green and Co; 1956.

7. UNESCO.Roadmap for Implementing the Global Action Programme on Education for Sustainable Development. France: United Nations Educational, Scientific, and Cultural Organization (UNESCO); 2014.

8. UNICEF. Ringkasan Kajian

Pendidikan dan

Perkembangan Anak Usia Dini. Jurnal Pendidikan. Jakarta: Unicef; 2013.

9. Mustika NRW. Perbedaan perkembangan motorik sosial dan bahasa pada toddler antara yang mengikuti PAUD dan tidak mengikuti PAUD di Kelurahan Nglorog, Sragen; 2011. 